\title{
A Sex Work Research Symposium: Examining Positionality in Documenting Sex Work and Sex Workers' Rights
}

\author{
Megan Lowthers ${ }^{1, *}$, Magdalena Sabat ${ }^{2}$, Elya M. Durisin ${ }^{3}$ and Kamala Kempadoo ${ }^{4}$ \\ 1 Centre for Refugee Studies, York University, Toronto, ON M3J 1P3, Canada \\ 2 Institute Without Boundaries, George Brown College, Toronto, ON M5A 1P4, Canada; \\ magdalena.sabat@georgebrown.ca \\ 3 Department of Political Science, York University, Toronto, ON M3J 1P3, Canada; edurisin@yorku.ca \\ 4 Department of Social Science, York University, Toronto, ON M3J 1P3, Canada; kempadoo@yorku.ca \\ * Correspondence: lowthers@yorku.ca
}

Academic Editor: Leslie Jeffrey

Received: 20 February 2017; Accepted: 26 March 2017; Published: 5 April 2017

\begin{abstract}
Historically, academic literature on sex work has documented the changing debates, policies, and cultural discourse surrounding the sex industry, and their impact on the rights of sex workers worldwide. As sex work scholars look to the future of sex workers' rights, however, we are also in a critical moment of self-reflection on how sex work scholarship engages with sex worker communities, produces knowledge surrounding sex work, and represents the lived experiences of sex workers' rights, organizing, and activism. In this short Communication, proceedings from a recent sex work research symposium entitled, Sexual Economies, Politics, and Positionality in Sex Work Research are presented. Held at the Centre for Refugee Studies at York University, this symposium is a response to the need for sex work researchers, sex workers, and sex worker-led organizations to come together and critically examine the future of research on sex work and the politics of documenting sex workers' rights.
\end{abstract}

Keywords: conference proceedings; sex work; sex workers' rights; research methods; reflexivity; positionality; sexual economies; technology

\section{Introduction: Positionality in Sex Work Research}

Historically, academic literature on sex work has documented the changing debates, policies, and cultural discourse surrounding the sex industry, and their impact on the rights of sex workers worldwide. The contemporary moment in sex work research has culminated in various special issues and collections such as this one, reflecting sex worker politics amid neoliberal transformations (Bernstein 2014), governance and policing (Sanders and Campbell 2014), transnational migration and trafficking (Kempadoo et al. 2005), and culture, health, and sexuality (Allman and Ditmore 2016). As sex work scholars look to the future of sex workers' rights, however, we are also in a critical moment of self-reflection on how sex work scholarship engages with sex worker communities, produces knowledge surrounding sex work, and represents the lived experiences of sex workers' rights, organizing, and activism (Dewey and Zheng 2013, cf. Van der Meulen et al. 2013).

In this short Communication, one recent response is presented emphasizing the need for sex work researchers, sex workers, and sex worker-led organizations to come together and examine the future of research on sex work and the politics of documenting sex workers' rights. This response took the form of a sex work research symposium entitled, Sexual Economies, Politics, and Positionality in Sex Work Research. The symposium brought together diverse voices engaged in sex work research: 
academic researchers (students and faculty) and community-based researchers and activists. Several of the symposium's participants identified and worked in both of these categories, being involved in research in and outside of the academy and/or practicing sex work. Held at the Centre for Refugee Studies at York University, and owing to the strong support for sex work research by the Centre for Feminist Research, the purpose of this symposium was to critically examine and debate positionality in sex work research.

This forum was co-organized by York University Professor Kamala Kempadoo, a leading scholar on sexual labour and sex workers' rights, and sex work researchers Elya M. Durisin, Magdalena Sabat, and Megan Lowthers. In addition to the organizers, the symposium included nearly 30 participants from Toronto and Ontario, representing York University, Ryerson, the University of Toronto, and Western, Brock, and Carleton Universities. Local sex workers' rights organizations were also represented among the participants, including Maggie's: The Toronto Sex Workers Action Project and Butterfly (Asian and Migrant Sex Workers Network) (see Figure 1). Committed to examining positionality in sex work research in innovative and participatory ways, the symposium included three collaborative roundtable discussions steered by the symposium organizers to promote participants' engagement with key sub-themes in sex work research in relation to their own subject positions, activism, and research agendas. Following the event's keynote address by internationally renowned sex work scholar Professor Adriana Piscitelli from the University of Campinas in Brazil, participatory discussion was facilitated by the symposium organizers and surrounded the sub-themes of intersectionality, sexual economies, and new technologies in sex work and sex work research.



Figure 1. Sex work research symposium organizers and participants.

\section{The Keynote: Knowledge Production in Sex Work Research}

The sex work research symposium opened with a keynote address examining positionality, politics, as well as alliances and tensions in the production of knowledge within the field of sex work studies, on which Piscitelli has published widely in the context of the Brazilian sex industry (cf. Piscitelli 2014) Piscitelli discussed how the subject positions of sex work researchers influence the research design, data collection, relationships with participants, and processes of research dissemination through an account of her own fieldwork in Brazil and Portugal, where she worked for the Brazilian government, researching the sex industry practices of migrant Brazilian women. She noted that reflecting on one's own subject position and power dynamics inherent within knowledge production on sex work research is not as theoretically challenging as the political implications of how this knowledge is used. In Piscitelli's account, the most challenging aspect of research was navigating the contesting interpretations of her work, in particular the interpretations and conclusions drawn from her research by the public body she was representing. 
Piscitelli's keynote address opened the symposium up to the subject of positionality and how critically important it is to practice reflexivity, in terms of a researcher's class, race, gender, sexuality, and age, and how greatly these impact the research setting and its outcomes. Further, the keynote address also opened the symposium up to the issue of participatory research and academic knowledge that examines the subject positions produced by sex workers themselves (Love 2013). Sex workers and their organizations, Piscitelli noted, are often wary of non-sex worker research, calling into question when, and how, the academic production of knowledge can be made relevant through applied research, activism, and advocacy for sex workers' rights.

\section{The Roundtables}

\subsection{Subject Positions, Intersectionality, and Shaping Research Agendas}

In the first roundtable of the sex work research symposium, participants examined issues surrounding authenticity and legitimacy in the production of knowledge about sex work and sex workers' rights. As sex work studies have expanded as an interdisciplinary field, space has been created for sex workers to question the motivations surrounding sex work research and the legitimacy of academics conducting the research. In this forum, participants were given the opportunity to share their own experiences of positionality in relation to sex work research and activism and in relation to practicing sex work itself. These experiences included the fluidity of sex worker and sex work researcher, the authority that sex work activities can secure in research contexts, and the difficulties that sex workers who also conduct research face in both their academic institutions and activist organizations. Many of the participants who identified only as sex work researchers agreed that they questioned their value as an ally to sex workers and the sex workers' rights movement in constant negotiation with how to produce research that can be valued in both academia and the sex worker community. While some participants came to sex work research through activism, others found activism through sex work research; however, almost all participants felt an obligation to participate in feminist debates surrounding sex work and labour markets and engage in social justice activism and/or policy-relevant research.

One participant raised the point that reflexively examining the subject-position of the self in relation to sex work research was almost exclusively a Canadian/Western practice, noting that in her experience working in Asia, positionality was usually defined as political alliance rather than through categories of race, class, and gender of the individual researcher. Hence, while most participants agreed on the importance of reflexively examining their subject-positions, often at multiple points or even in on-going ways and appreciated the opportunity to further examine positionality in reflexive dialogue with other sex work researchers, they also debated how best to approach and capture categories of difference and positionality, and how to incorporate the implications in knowledge production. Despite the lack of research on, and representation in the symposium of, racialized and Indigenous sex workers, participants felt that reflecting on their own positionalities and sharing their experiences of knowledge production were important for addressing the myriad categories of difference in sex work.

\subsection{Examining Sexual Economies, Research, and Activism}

In the second roundtable of the symposium, participants examined sex work research and activism using the framework of sexual economies, a term used to capture the notion of sex markets, which can include material and/or symbolic sexual exchanges for sexual services, as well as the larger social, economic, and geographical context in which they take place (for a concise review of this concept, see Piscitelli 2016, cf. Lowthers 2018). Given the diversity of sex work practices and experiences that make up sexual economies, participants were asked to give insights into the categories and terminology we use to understand and theorize sexual labour and how this extends to sex work research and sex workers' rights activism. Roundtable discussants and participants represented research and activism spanning the spaces of Amsterdam's global red light district (Sabat 2012), the cultural dynamics of 
Devadasi sex work in India (Orchard 2007), and sex worker migration and deportation from Canada (for an overview of the activist work of the Migrant Sex Worker's Project and Butterfly, see Simon 2015). Sex work researchers have been addressing the diversity of practices covered under the term "sex work" and the complexity of its economic and social organization, including its highly global and neoliberal structure, state supported models, and its connection to the hospitality and tourism sectors (Kelly 2008).

The relevance of the term "sex work" was debated, given that persons who engage in sexual labour do not consistently use the term or identify with it. Therefore, symposium participants questioned whether current terminology is complex enough to theorize workers' experiences and whether the language of the academy distances researchers from the work of activist organizations. Considering the changing notions of sexuality, social norms, and the prevalence of neoliberal processes in the sex industry, symposium participants all emphasized the need to find new ways to theorize the realities of sexual economies and sexual labour as dynamic and changing lived experiences. The result of this disconnect between academic theorizations and activism is that sex work research risks becoming distanced from agendas most crucial to the lives of those who perform or engage in sexual labour. This is reinforced by the economics of academic research, which restrict research agendas to issues that are most prominent in political debates and do not necessarily reflect the immediate concerns of communities engaging with sexual economies. Given that the symposium converged around the present state of vastly fractured feminisms and that the language of sex work research in the academy reflect these divisions, participants searched for ways to navigate through these tensions and binaries. This was envisioned by enabling new forms of political and social organizing and improved cooperation among those who perform or engage in, research, advocate, and/or disseminate information about sexual labour, creating new forms of cooperation among practitioners, researchers, activist organizations, governments, the media, and local communities.

\subsection{Research, Knowledge Production, and New Technologies}

In the third and final roundtable of the symposium, participants explored how new and emerging technologies are impacting the sex industry and sex workers' rights, and how the complexities of sexual economies and markets are being researched. As the sex worker community, their clients, sex worker-led organizations, feminist movements, the state, and the public increasingly interface with technology, the sex industry has diversified and transformed in how it is marketed, portrayed and perceived, and practiced. Changing markets in the sex industry due to technological innovations, such as online client solicitation through web sites, e-mail, cell phones, applications, and social media have made the Internet critical to the sex industry. However, researchers have yet to fully grasp how the sex industry has diversified along technological lines (Bernstein 2007). Roundtable discussants and participants represented innovative research on the implications that new technologies have had for sex workers' experiences of gender relations in Kenya (Lowthers 2015), global labour markets (Zen 2016), and in both spatial practices and subjectivity (Orchard et al. 2016) and surveillance and community safety (Wright et al. 2015) within Canada.

While clearly creating new opportunities for research, technology also provides a new medium for self-representation and participation in the local and global sex workers' rights movement. However, all symposium participants agreed and emphasized that technology has uneven effects on persons engaged in sexual labour and sex workers' rights in ways that can be both empowering and disempowering. Not only does new technology provide better and more efficient tools for communication, organizing, money management, and safety and security, it is also connected to new forms of regulation, criminalization, marginalization, and discrimination. Furthermore, new technologies have also become highly contested tools that shape both public and academic perceptions of sexual labour and the sex industry, as people who work in the sex industry are now able to produce their own knowledge but cannot control how this knowledge is used. Participants of the symposium recognized that there is a need for more research on emerging issues surrounding new technologies 
and the virtual spaces of sex work, changing sexual-economic relations, as well as the significant impact technology has had on sex work research in its design, methodologies, ethics, and activism.

\section{Conclusions}

This research symposium provided a unique opportunity to share diverse perspectives across disciplines, sectors, and communities on knowledge production and research practices in sex work studies today. In each roundtable session, participants' awareness of positionality as researchers, activists, and allies of the sex workers' rights movement, and reflections on subjective investments in the research process were facilitated. The symposium also offered a space to discuss divisions in feminist politics as a whole, wherein sex work research continues to be framed along binaries, especially victimhood versus agency. Looking to the future of research on sexual economies, sexual labour, and sex workers' rights, such participatory and reflective forums are critical to providing new insight into the relationship between positionality and knowledge production in this field of sex work research, while also fostering better collaborations among academics, workers, and community-based organizations.

Acknowledgments: The organizers and participants extend their appreciation to the Centre for Refugee Studies at York University, which hosted and supported this important event, as well as to the following organizations within York that provided funding: FLA\&PS Research Office, the Centre for Feminist Research, the Centre for Research on Latin America and the Caribbean, the Global Labour Centre, the Department of Social Science, the School of Gender, Sexuality, and Women's Studies, and the Graduate Program in Gender, Feminist, and Women's Studies.

Author Contributions: Megan Lowthers wrote this communication based on the report from the symposium with contributions from Magdalena Sabat and feedback, comments, and revisions provided by Elya M. Durisin and Kamala Kempadoo.

Conflicts of Interest: The authors declare no conflict of interest.

\section{References}

Allman, Dan, and Melissa Hope Ditmore. 2016. Introduction to the Culture, Health \& Sexuality Virtual Special Issue on Sex, Sexuality and Sex Work. Cult Health Sex 18: 1-8.

Bernstein, Elizabeth. 2014. Introduction: Sexual Economies and New Regimes of Governance. Social Politics: International Studies in Gender, State \& Society 21: 345-54.

Bernstein, Elizabeth. 2007. Temporarily Yours: Intimacy, Authenticity, and the Commerce of Sex. Chicago: The University of Chicago Press.

Dewey, Susan, and Tiantian Zheng. 2013. Ethical Research with Sex Workers: Anthropological Approaches. New York: Springer. Kelly, Patty. 2008. Lydia's Open Door: Inside Mexico's Most Modern Brothel. Berkeley: University of California Press.

Kamala Kempadoo, Jyoti Sanghera, and Bandana Pattanaik, eds. 2005. Trafficking and Prostitution Reconsidered: New Perspectives on Migration, Sex Work, and Human Rights. New York and London: Routledge.

Love, Victoria. 2013. Champagne, Strawberries, and Truck-Stop Motels: On Subjectivity and Sex Work. In Selling Sex: Experience, Advocacy, and Research on Sex Work in Canada. Edited by Emily van der Meulen, Elya M. Durisin and Victoria Love. Vancouver: UBC Press, pp. 58-64.

Lowthers, Megan. 2015. Sexual-Economic Entanglement: A Feminist Ethnography of Migrant Sex Work Spaces in Kenya. Ph.D. thesis, The University of Western Ontario, London, ON, Canada.

Lowthers, Megan. 2018. On Institutionalized Sexual Economies: Employment Sex, Transactional Sex, and Sex Work at Kenya's Cut Flower Industry. Signs: Journal of Women in Culture and Society, in press.

Orchard, Treena. 2007. In This Life: The Impact of Gender and Tradition on Sexuality and Relationships for Devadasi Sex Workers in Rural India. Sexuality \& Culture 11: 3-27.

Orchard, Treena, Jennifer Vale, Susan Macphail, Cass Wender, and Tor Oiamo. 2016. "You Just Have to Be Smart": Spatial Practices and Subjectivity among Women in Sex Work in London, Ontario. Gender, Place E Culture 23: $1-14$.

Piscitelli, Adriana. 2016. Sexual Economies, Love and Human Trafficking-New Conceptual Issues. Cadernos Pagu 47: 1-30.

Piscitelli, Adriana. 2014. Transnational Sisterhood? Brazilian Feminisms Facing Prostitution. Latin American Policy 5: 221-35. [CrossRef] 
Sabat, Magdalena. 2012. From Red Light to Black Light. City 16: 158-71. [CrossRef]

Sanders, Teela, and Rosie Campbell. 2014. Criminalization, Protection and Rights: Global Tensions in the Governance of Commercial Sex. Criminology and Criminal Justice 14: 535-48. [CrossRef]

Simon, Caty. 2015. Activist Spotlight: The Migrant Sex Workers Project on Borders and Building Movements. Tits and Sass, October 14. Available online: http://titsandsass.com/activist-spotlight-the-migrant-sexworkers-project-on-borders-and-building-movements-part-one/ (accessed on 20 February 2017).

Emily Van der Meulen, Elya M. Durisin, and Victoria Love, eds. 2013. Selling Sex: Experience, Advocacy, and Research on Sex Work in Canada. Vancouver: UBC Press.

Wright, Jordana, Robert Heynen, and Emily van der Meulen. 2015. "It Depends on Who You Are, What You Are": 'Community Safety' and Sex Workers' Experience with Surveillance. Surveillance E Society 13: 265-82.

Zen, Kate. 2016. Sex Work, Technology, Labour Markets, and Knowledge Production. Available online: http:/ / www.slideshare.net/KateZen/sex-work-technology-labour-markets-and-knowledge-productionkate-zen (accessed on 20 February 2017).

(C) 2017 by the authors. Licensee MDPI, Basel, Switzerland. This article is an open access article distributed under the terms and conditions of the Creative Commons Attribution (CC BY) license (http:// creativecommons.org/licenses/by/4.0/). 